\title{
Por uma leitura crítica da linguagem publicitária em sala de aula
}

Márcia Elisa Teté Ramos*

\section{RESUMO}

0 presente artigo propõe a discussão da função pedagógica da cultura midiática nas sociedades modernas. Sugere a pesquisadores, professores e estudantes a urgente necessidade de transformar a mídia em objeto de estudo no âmbito das práticas pedagógicas escolares, focalizando principalmente a publicidade no ensino de História.

Palavras-chave: cultura midiática, ensino de História, publicidade.

\section{Introdução}

Tomando como referência amplo material bibliográfico especializado vindo do exterior, Rui Barbosa, então relator da Comissão de Instrução Pública, elabora um parecer acerca do documento Reforma do ensino primário e várias instituições complementares da instrução pública (1883). Em seu parecer, preconizava o ensino de História desde às primeiras letras, que deveria ter como conteúdo os grandes fatos da História nacional, e, como em outras disciplinas escolares, a metodologia deveria corresponder ao desenvolvimento do espírito científico na criança. Em História, este "espírito científico" implicava no uso de fontes historiográficas: "ninguém, ao parecer, refletiu ainda que os verdadeiros elementos da história não consistem ao fato de referir histórias, mas na aquisição de noções elementares acerca dos documentos e da maneira de apurá-los" Rui Barbosa considerava que o livro não era suficiente para inclinar "o menino para o verdadeiro sentimento de história" (BARBOSA apud SOUZA, 2000, p.23). 0 argumento de Rui Barbosa inscrevia-se no ideário em voga em seu tempo: da escola enquanto instrumento de modernização/ civilização. Seguindo essa premissa, a escola deveria ser obrigatória, gratuita, laica,

\footnotetext{
* Professora de "Metodologia e Prática de Ensino de História" da Universidade Estadual de Londrina
} 
alicerçar seus conteúdos visando a formação do amor à pátria, e utilizar o método intuitivo, em que o conhecimento das coisas é possível pelos sentidos, mediante observação, comparação e classificação das experiências (SOUZA, 2000). Calcada nesta perspectiva, a prescrição de Rui Barbosa em se trabalhar com documentos históricos em sala de aula advinha da necessidade de fazer com que 0 aluno tivesse acesso direto ao material que sustentaria a cientificidade da História, ou seja, a verdade presente nos documentos.

0 uso do documento histórico em sala de aula, tantos anos depois do parecer de Rui Barbosa apresenta-se como atual e pertinente, levando-se em conta que no momento histórico que vivenciamos os debates nesta direção pressupõem outra noção de ciência, de ensino e de História. Tornou-se fundamental, tanto nos escritos sobre ensino de História como nos currículos atuais que conhecê-la implicaria na apropriação dos processos através dos quais a sua escrita é realizada. Schimidt \& Garcia concluem através dos pontos divergentes e consensuais de Zaragoza (1989) e Iglesias \& Perez (1994) que na investigação como método de ensino da História, o aluno passará a conceber a História como ciência com metodologia própria que muda com o tempo, como conhecimento sempre parcial dado pelos documentos que supõem versões. E ainda: não se trata de converter o aluno em historiador, mas fazer com que aprendam História pelo trabalho com o documento sob a organização, seleção e estratégias do professor (SCHMIDT \& GARCIA, 2003). Para Bernard Charlot, todo ensino digno desse nome pretende formar para a prática do saber. Sendo assim, o educador a ministrar uma disciplina, pratica o saber diante dos alunos e supõe que estes, seguindo-o passo a passo, aprendam a pensar (CHARLOT, 2005, p.91).

Seguindo a noção em curso de documento histórico, que engloba todo tipo de registro, depoimentos e testemunhos contidos em textos, imagens, paisagens, sons, construções, objetos e costumes, encontramos muitos pesquisadores do ensino de História e/ou professores de História que escreveram sobre, ou levaram para a sala de aula uma gama variada de fontes documentais como, por exemplo, música, estória em quadrinhos, filmes, documentários, fábulas, revistas, fotografias, charges e artes plásticas, mas pouco se tem considerado a publicidade. Mesmo que se advogue no ensino de História a perspectiva de que a realidade imediata do aluno seria importante para a 
motivação do conhecimento, mote para problematizações e relações entre presente e passado, a publicidade (hoje tão entremeada no cotidiano) não é contemplada, talvez pela idéia de que esta não traria em si "conteúdos históricos" ou então seria marcada pela fragmentação, efemeridade e imediatismo: portanto, sem correspondência com o passado.

Quando se diz "leitura crítica" em relação à linguagem publicitária, estamos entendendo que trataremos a publicidade enquanto documento histórico em sala de aula, e também, que esse procedimento apontaria para uma leitura que pretende ir além do que nos é dado de imediato, em um exercício de reflexão. Se considerarmos que o trabalho com a publicidade como documento histórico em sala de aula significa entender que esta faz parte da realidade do aluno e (também) permite desenvolver o raciocínio histórico, algumas indagações nos assaltam: como se configura essa realidade? Como superar o tempo pontual e super-fracionado da publicidade dando-lhe significação histórica? Não existe referenciação teóricometodológica suficiente sobre a utilização da publicidade no ensino de História, o que nos deixa em uma posição tateante e provisória. Assim, buscaremos muito mais instigar do que dar respostas conclusivas. Neste sentido, buscaremos, em um primeiro momento, considerar a questão da cultura midiática em que o aluno estaria inserido. Posteriormente, indicar a questão da publicidade e as novas relações com o saber que esta implica. Finalmente, indicar algumas das possibilidades de trabalho com a publicidade como documento histórico para uso escolar em ensino de História.

\section{Cultura midiática}

Sobre a realidade em que todos nós estamos inseridos, podemos inferir, considerando o macro-nível, que estamos na chamada "era da globalização", que seria um padrão econômico, político e cultural que se alastra em escala planetária mesmo seguindo ritmos diferenciados, em que a produção, a circulação e o consumo de formas simbólicas através dos meios de comunicação passam a ocupar um lugar fundamental, pois: 1) seriam indispensáveis para sustentar os circuitos globais de acumulação, concentração e expansão do capital, e 2) teriam a capacidade de difundir imagens, idéias e informações em várias sociedades, atingindo um grupo cada vez maior de pessoas, interferindo 
de forma decisiva no cotidiano. Globalização (não necessariamente mundializada) estaria correlacionada com a "cultura midiática": a cultura de mercado, (constituída por rádio, cinema, televisão, música e imprensa) pensada, produzida e disseminada por intermédio dos conglomerados empresariais da comunicação, da informação e do entretenimento, que mediante sofisticação tecnológica, facilita a constituição de novas instâncias geradoras de sentido (MOREIRA, 2003). Sua marca, seu "coração", no sentido de ser a parte mais central, pulsante e que produz movimento, é a publicidade.

No mundo atual, grande parte dos significados, experiências, referências valorativas e comportamentais tendem a serem reconhecidos e internalizados socialmente depois de serem incorporados pela mídia. Neste ponto chegamos à grande controvérsia quanto à cultura midiática. Alguns autores ainda creditam à mídia o (todo)poder de produzir ou refletir interesses dos grupos economicamente dominantes. Em acordo com tal noção, o receptor, o público sobre o qual se destinam os artefatos culturais seria um sujeito apático, existiria uma massa passiva diante das mensagens da mídia e facilmente conformada por estas. Assim, para Emil Vlajki (2001) a mídia é parte do totalitarismo ocidental onde se fabrica e se vende a realidade e o consenso.

Outro grupo de teóricos, baseando-se nos trabalhos sobre o cinema, como 0 de Christian Metz (1978) o investiga pela linguística e semiótica destacando 0 universo da comunicação e as relações entre texto fílmico/realidade/espectador, considerando a noção de audiência ativa, critica a visão mecanicista que ressalta o poder manipulador da mídia. Outros teóricos do cinema, seguindo esta direção, passaram a adotar o conceito de "modo de endereçamento", compreendendo que a produção de um filme visa atingir determinados espectadores reais ou imaginados, mas seria impossível prever e controlar totalmente o processo de recepção, leitura e reação destes (ELLSWORTH, 2001). As mudanças que se percebem na forma de compreensão sobre a mídia devem-se também ao território conceitual historiográfico, como por exemplo, Roger Chartier que entende a produção dos objetos culturais entre práticas e representações, em que os sujeitos produtores e receptores da cultura circulariam entre esses dois pólos permeados pelas relações de poder. Assim, se existe um texto como dispositivo que busca operar uma construção de sentido de modo a normatizar práticas, o mesmo pode ser diversamente apreendido, manipulado e compreendido pelos indivíduos ou grupos, conforme a pluralidade de suas posições 
sócio-culturais. Outros sentidos, outros usos diferentes daqueles do "horizonte de expectativas" do texto, podem ser construídos pelos destinatários (CHARTIER, 1991).

Nessa vertente, a influência da mídia não pode ser vista como necessariamente negativa, como doutrinação rígida que induz sempre à concordância, como queriam algumas abordagens reducionistas sob uma determinada leitura marxista ou comportamental-behaviorista (PAULA, 1998, p. 132). A influência da mídia não significaria uma relação direta de causa e efeito entre o que é mostrado e um comportamento repetido, de maneira que não teria autoridade de fabricar uma cultura que é forçada ao sujeito. Este é visto como produtor ativo de sentido, que interpreta os materiais midiáticos conforme seus próprios códigos culturais criados em uma formação social determinada, em que também pesam sua classe, gênero, idade, religião, profissão e etnia.

Entre duas abordagens tão diversas, uma que potencializa a mídia como instância transmissora da ideologia dominante e outra que pode extremar a autonomia da "apropriação", vem se forjando uma perspectiva intermediária que James Curram (1990) denomina "novo revisionismo". Esta tendência teốrica não descarta as contribuições dos analistas de cinema e dos historiadores ligados à História Cultural, antes, os retoma principalmente no que diz respeito à noção de que a cultura nunca está apartada do conjunto de relações sociais hierarquizadas e antagônicas, e por isso constitui um terreno de disputa, portanto contraditório, múltiplo e híbrido. Assim, os "novos revisionistas" acreditam que o discurso da mídia, embora não seja assimilado pelo espectador em sua acepção literal, possui a finalidade de transmitir determinados significados tidos como preferenciais em detrimento de outros (PAULA, 1998, p.137-138). A perspectiva sobre a audiência como produtora ativa de sentido, se levada ao exagero, subestimaria ou mesmo apagaria a possibilidade da mídia de interferir, mesmo que parcialmente, nos valores, projetos, opiniões e ações do sujeito.

Concordamos com essa perspectiva que vê a relação do sujeito com a mídia em um processo complexo e que envolve uma atividade contínua tanto de assimilação, cumplicidade e aceitação quanto de re(elaboração), transgressão, oposição e re(significação). No entanto, se a recep̧̧ão dos significados veiculados pela mídia não se pode dominar por completo, consideramos que a linguagem publicitária dificilmente propicia leituras oposicionais, pois estamos lidando com mensagens que servem ao propósito 
último de vender algum produto, serviço ou idéia, e que por isso busca a eficácia em sua estratégia de convencimento. A linguagem publicitária não poderia ser óbvia em sua determinação em cooptar o consumidor, mostrando suas verdadeiras intenções, por isso utiliza-se de recursos de persuasão e sedução, explorando o universo dos desejos. Desta forma, a publicidade tende a reter do espectador um olhar mais "maravilhado" do que "atento". Para detectar 0 que dará satisfação ao consumidor, não apenas sondagens quantitativas são realizadas, mas sofisticadas pesquisas qualitativa-etnográficas que exigem dos profissionais da mídia publicitária, além dos saberes da ciência da comunicação, um conjunto de saberes tais como o do sociológico, do antropológico, do psicológico, do histórico-cultural, do lingüístico, etc. 0 olhar do espectador/ consumidor precisa ser atentamente perscrutado para se criar um "mundo mágico" que tanto o encanta como atrai.

A publicidade é uma esfera relativamente padronizada a partir do sujeitoconsumidor e que faz com os indivíduos demarquem seus perfis, seus papéis sociais, ao se posicionarem enquanto pertencentes ou não ao grupo que consome: "...quando selecionamos os bens e nos apropriamos deles, definimos o que consideramos publicamente valioso, bem como os modos com que nos integramos e nos distinguimos na sociedade, com que combinamos 0 pragmático e o aprazivel" (CANCLINI, 2001, p.45). Esse consumo que confere identidade não se restringe à compra daquilo de que se necessita, mas requer também a apropriação de características intangíveis, exteriores ao produto: "Para tornar-se objeto de consumo é preciso que o objeto se torne signo" (BAUDRILLARD, 2000, p.207). 0s produtos ultrapassam sua finalidade de uso, dando respostas para carências, desejos, ilusões, medos e sonhos dos consumidores, prometendo prazer, felicidade, inteligência, segurança, charme, sofisticação, liberdade, juventude, poder, reconhecimento, abundância, renovação, atratividade, etc. Deste modo, a publicidade vende muito mais do que mercadoria: vende a promessa de uma necessidade (fabricada?) ou aspiração, que extrapola, em muito, as possibilidades de um produto. Adquirese o produto por aquilo que ele representa, pelo seu valor simbólico, pelo seu suposto preenchimento de um vazio existencial e, ao mesmo tempo, o produto nomeia, significa o consumidor, lhe confere identidade, valorização/ reconhecimento social e signos de prestígio. Buscando o consumo de produtos 
"personalizados", os consumidores projetariam seus desejos na mercadoria, e então por intermédio de sua posse se expressariam, emprestando destas suas qualidades (GUIMARÃES, 2003, p.31).

Mesmo que uma publicidade não cause o efeito desejado aumentando a venda de determinado produto, é um modo de vestir, falar, agir, pensar, que se não são "vendidos", formam o ser que compra. Neste sentido, segundo Baudrillard, os produtos tornam-se "álibis" para a produção de uma cultura regulada pelo consumo: a publicidade não veicula somente modelos de roupas, maquiagens, cervejas, carros, refrigerantes, etc., mas a atitude de consumo, modos de apresentação pessoal, de relacionamentos e de comportamentos, modos de vida e pensamento (BAUDRILLARD, 2000, p. 175).

A publicidade quer atingir qualquer tipo de possivel consumidor, seja ele de qual poder aquisitivo, idade, gênero, região, religião e etnia que pertença. Mas se as "diferenças" são importantes para a elaboração da publicidade, o que se almeja para os consumidores seria homogeneizá-los, considerando-se os nichos de mercado, em que cada um desses nichos é definido segundo uma identidade de consumidor particular. Identidades étnicas e até mesmo a identidade de classe tornaram-se ligadas aos produtos e imagens que se quer vender (CARLSON \& APPLE, 2003, p.35). A contrapartida da busca da identidade pelo consumo seria a necessidade de diferenciação dos demais, dos excluídos do consumo, em uma cadeia de discriminação e hierarquização dos grupos sociais.

\section{Novos saberes na cultura midiática}

Neste contexto, qual seria o espaço ocupado pelas crianças e adolescentes? Antes de qualquer coisa, devemos lembrar que a infância e adolescência são conceitos construídos historicamente. No processo de consolidação do capitalismo, a criança foi colocada como dependente do adulto, na medida em que não está inserida no processo de produção. Tratada como ser incompleto, precisava ser educada segundo a lógica dessa concep̧̧ão. Nas sociedades ocidentais contemporâneas (a partir da segunda metade do século XX), a infância se transforma, se desromantiza, não é mais lugar da felicidade e inocência quando se envolve em esferas tidas como próprias aos adultos: 0 
trabalho, o erótico e o crime (CAMPOS, 2002). Essa infância transmuta-se principalmente quando a mídia vai conquistando a condição de co-partícipe da escola e da família na formação de valores e referenciais culturais, na construção de novos padrões identitários. A infância como construção social atrelada às demandas da produção capitalista, agora se constitui sob outros parâmetros, vinculados ao deslocamento da produção para o consumo. Para a publicidade, a criança não é mais tratada como filho de cliente, mas ostenta o status de cliente, um sujeito que tem opinião, que gasta, consome é exigente.

Assim como a infância, as formas sociais do tempo e do saber que nos parecem ser as mais naturais e incontestáveis, baseiam-se sobre o uso de técnicas historicamente datadas e, portanto, transitórias. Da revolução da passagem da oralidade à escrita, separa-se o emissor do receptor, vê-se a impossibilidade de interagir. A escrita, em relação à oralidade, é despersonalizada, torna-se abstrata, transforma o tempo em uma concatenação de causa e efeito. Enquanto tecnologia intelectual, o aparato textual condiciona outras formas de pensamento e aprendizagem, orienta um raciocínio, implica princípios e conceitos (LÉVY, 1993; MUNAKATA, 2003). Porque com o advento da cultura midiática a temporalidade e as relações com o saber também não mudariam?

Enquanto que os anúncios do começo do século passado (nos cartazes, rádios, jornais e revistas), detalhavam o propósito do produto, com dados relativos ao preço, às vezes o nome do inventor, local em que era comercializado, sua suposta aprovação por instância governamental, etc., atualmente as pessoas não podem dispor de tempo para ler ou escutar, não estão mais acostumadas esse tipo de narrativa. Com a linguagem a publicidade da cultura midiática, utiliza-se muito mais da persuasão e sedução do que da objetividade informativa. A publicidade precisa ser prazerosa de ver, agradável de ouvir, rápida de compreender, sem exigir grandes esforços de reflexão do espectador/consumidor. A mídia publicitária tanto reflete como constrói um modo de pensar e agir, próprio de uma sociedade mais dinâmica, mais móvel, e mais voltada para 0 consumo/prazer imediatos. Estar neste mundo e com ele se ligar, exige novas formas de percepção, de relação com o saber, de sensibilidades.

A criança e 0 adolescente de hoje já nasceram na cultura midiática, não precisam como o adulto, de se adequarem a ela, e parecem prescindir do adulto como fonte de informações. 
Enquanto para 0 adulto tais transformações tecnológicas se apresentam filosoficamente como um problema e implicam sempre uma readequação dos modos de pensar e de viver, para a criança elas se apresentam como constituintes quase que imediatas da sua vida psíquica e tomam a forma de brinquedo a ser explorado de maneira lúdica (PEREIRA, 2002, p. 161).

0 desprendimento com que a criança e o jovem lidam com a mídia moderna, principalmente com a televisão, os colocam em uma posição de independência frente ao adulto. Por vezes é o adulto que se torna inapto ao necessitar da criança e do adolescente para traduzir os significados de uma cultura que lhe parece estranha. Esse estranbamento acontece visto que as transformações tecnológicas não oferecem imediatamente a consciência do seu significado àqueles que a produziram, mas para as novas gerações tais transformações já se apresentam em forma de cultura (PEREIRA, 2002). Diferente da linguagem escrita, pautada em uma lógica linear que apresenta efeitos cognitivos-conceituais, cuja aprendizagem coloca a criança como sujeita ao ensinamento do adulto, a cultura midiática, em especial a publicidade, atua mais fortemente de maneira afetiva-relacional, não exigindo uma formação prévia para seu entendimento. Por esse pressuposto, a publicidade não necessitaria do sujeito mediador, condição imprescindível à aprendizagem da escrita ou da oralidade.

No entanto, a nosso ver, o papel da escola seria também o de trabalhar com as novas relações com o saber que caracterizam a cultura midiática, agora tendo em vista que a criança e o adolescente experimentam a descontinuidade, a sobreposição, a superficialidade, a dispersão, a simultaneidade e a hiper-realidade. 0 tempo posto pela mídia publicitária tem um ritmo muito mais veloz, um mundo muito atraente e convincente da qual a escola tem dificuldade de apoderar-se, mas isso não dependeria de aparato técnico, nem de lamentar a "derrota do pensamento e das instituições", e sim de apreender esse real que está nascendo, acompanhar e buscar compreender o seu movimento, e trazê-lo para a sala de aula de forma que sua potencialidade positiva apareça (LÉVY, 1993, p.118).

Devido ao estatuto pedagógico da mídia, Kellner (1995) propõe o desenvolvimento de um "alfabetismo crítico em relação à mídia", ou seja, a 
necessidade de, na escola, se dar condições para que o educando possa elaborar uma leitura crítica dos textos, imagens, mensagens e espetáculos da mídia que permeiam nossa cultura. Essa leitura crítica implica em aprender como avaliar, decodificar e interpretar o discurso da publicidade, analisando tanto a forma como ele é construído e opera em nossas vidas, quanto o conteúdo de suas mensagens. Também Fischer (1998) destaca que as escolas ou outros espaços, deveriam fazer com que crianças e adolescentes pudessem encontrar referências suficientes para aprender a organizar, selecionar, hierarquizar o imenso volume de informações e significados midiáticos.

As crianças e os jovens são os mais expostos à publicidade, devido à quantidade de tempo que disponibilizam em frente à TV, ao apelo lúdico e fascinante da publicidade, à necessidade dessa faixa etária em ter um "senso de pertencimento". Os publicitários sabem muito bem disto: alguns produtos destinados ao consumo adulto são anunciados através de uma linguagem adequada ao público infanto-juvenil devido seu poder de convencimento em relação aos seus pais ou responsáveis. Levando em conta que o público infantojuvenil entenderia melhor a linguagem da publicidade, mas também que a recepção de qualquer produto midiático, como vimos, é um terreno movediço de re(apropriações), é que podemos argumentar à favor da necessidade de a escola aproveitar as "lacunas" para engendrar uma atitude crítica em relação à mídia, especialmente quanto à mensagem publicitária.

\section{Possibilidades de trabalho}

Deste ponto de vista, interessa-nos a historicidade da produção da publicidade, ou seja, a problematização de: sua origem, autoria, circunstâncias em foi elaborada, sua inserção temporal, relação com outros documentos, destinatário, simbolismo, composição, formato, estrutura discursiva, significado, finalidades, articulações com o processo histórico (FERRAZ, 1999, p.686/687).

Algumas possibilidades de trabalho com a mídia publicitária podem ser aventadas no ensino de História. A publicidade de uma determinada sociedade pode ser examinada, no intuito de desvelar quais eram os produtos, idéias e serviços anunciados e que, portanto, faziam parte daquele cotidiano 
(publicidade localizada em determinado período histórico). Por exemplo: os graffiti de Pompéia e Herculano, entre outras, do século I d.C., são inscrições em latim vulgar (para possibilitar a leitura de muitas pessoas) nas paredes da parte nobre dessas cidades, funcionando como jornais murais para informar a comunidade sobre temas diversos: slogans eleitorais, comerciais, anúncios dos próximos eventos no anfiteatro, dias e locais de feiras livres e mesmo textos opinativos ou jocosos (estes geralmente de caráter sexual). As mensagens eram geralmente escritas a carvão ou material de curta duração para que as paredes poderem ser reaproveitadas'. Qual o teor dessas mensagens? Para quem eram destinadas? Quem as escreviam? 0 que objetivavam vender? Quais as diferenças e semelhanças entre esses anúncios comerciais daquela época com os anúncios da cultura midiática?

Outra alternativa seria a de elencar um eixo temático sustentado por uma problemática (seleciona-se várias publicidades do passado para análise de um tema histórico). Exemplos: Como é construída a imagem do poder político? No ano 14 d.C., a esposa de Augustus encomendou a um artista a estátua do Imperador, representado como general romano em posição de comando. A estátua tinha $1,90 \mathrm{~m}$ de altura, e apresentava o Imperador com o rosto e o corpo forte de um jovem de 30 anos. Na realidade, o Imperador tinha 1,60 m e 76 anos de idade e não tinha constituição física de guerreiro. A imagem de "príncipe da paz" se fixou na sociedade romana e na História, mesmo que Augustos tenha chegado ao poder por meio de assassinatos, devastação, perseguições e um golpe de estado brutal. Uma pintura retrata 0 rei francês Luís XIV, em 1701, em seus trajes de coroação, cercado pelos símbolos religiosos, político-militares que identificariam seu poder absolutista: cetro (força e autoridade), coroa (soberania), mão da justiça (poder de julgar, condenar e absolver), manto de pele de arminho (proteção, e pureza moral), espada (bravura guerreira) e trono (centro do poder e do reino), flor-de-liz (monarquia francesa) $)^{2}$. Seguindo essa linha, como Hitler era representado? Como Getúlio Vargas aparecia nas propagandas? Como o governo Collor foi construído pela

1 Algumas inscrições podem ser obtidas no site http://www.kke.org.br/index.html

2 Apoderei-me de imagens (e não da análise) dos livros didáticos de $5^{\mathrm{a}}$ a $8^{\mathrm{a}}$ séries do Ensino Fundamental: RODRIGUE, Joelza Ester. História em documento. Imagem e texto. $2^{\mathrm{a}}$ ed., São Paulo: FTD, 2002. Como o próprio título diz, a autora recorre a vários tipos de documentos históricos. 
mídia, primeiro como governo incorruptível, depois como o governo mais corrupto da História nacional? Como os políticos atuais se apresentam?

No caso da política atual, diz-se que o ideário do programa de um partido ou da atuação de um ou mais políticos interessaria menos do que seu marketing, isto é, os projetos propostos ou os resultados já obtidos seriam convertidos em objeto de oferta para o consumo no mercado eleitoral. Importaria a imagem de um candidato ou político, se este se apresenta bem no palco midiático, se se adaptaria às regras e procedimentos que configuram os dispositivos comunicacionais do mercado, enfim, se conseguiria "vender-se" não por seu conteúdo, mas pela sua forma política-teatral, pela publicidade de si (MATOS, 2002). A imagem certa, bem elaborada, conforme o conjunto de técnicas da época, a ser propagada/publicizada por poderes políticos de outros momentos históricos não quer também seduzir, arregimentar, atrair para seus propósitos? Quais as diferenças entre as imagens do poder veiculadas no passado e as de hoje? Considerando o uso da imagem para legitimação do poder em outras épocas, e atualmente, para realizar o marketing pessoal, sustenta-se a diferenciação entre o termo "publicidade", cujo objetivo restrito seria de vender produtos e serviços, e o termo "propaganda", mais relacionado ao campo das idéias, à mensagem política, religiosa e institucional?

A publicidade de um determinado item pode ser tomada na sua historicidade (a História da publicidade em consonância com a História). A publicidade de marcas a muito tempo no mercado, como "Coca-Cola", "Maizena", "Antárctica" ou "Gessy" podem ser vistas em suas mudanças e continuidades (cores, argumentos, imagens, escrita) relacionando-as aos momentos históricos que a produziram. Porque uma publicidade da década de 50 do século passado insistia em dizer que a água usada para fazer a "CocaCola" era "purísima", "filtrada pelos mais modernos e eficientes processos" e por isso tinha "gostinho de pureza"? Sobre a invocação de que "Por tráz da chapinha de Coca-Cola... um mundo de coisas boas", mostrando uma família feliz admirando uma cachoeira, pode-se perguntar quais semelhanças existem com a publicidade atual deste refrigerante? Uma publicidade do sabonete "Gessy" da mesma época diz que "82\% das mulheres brasileiras aprovam êste característico", exibindo uma mulher ao estilo de uma atriz hollywoodiana ${ }^{3}$.

3 Cartazes sobre várias marcas que contam a história da publicidade constam no site http:// www.memoriadapropaganda.org.br/ 
Porque esse estilo foi escolhido para caracterizar a mulher brasileira na época? Qual padrão de beleza feminina é empregada hoje na publicidade? Utiliza-se o apelo da nacionalidade brasileira ou uma pretensa pesquisa quantitativa sobre o gosto do consumidor nos anúncios atuais? Tanto na publicidade da "Coca-Cola" como do sabonete "Gessy" em sua trajetória no decorrer do tempo, quais os elementos que podem representar mudanças e permanências de um modo de vida e pensamento? Quais relações essas publicidades tinham com a História do Brasil e a História Geral?

A História Local pode ser pensada a partir da publicidade. No caso de Londrina ou do norte novo paranaense, qual o papel da publicidade difundida pela Companhia Norte de Terras do Paraná para o processo de colonização? A quem desejavam atingir? Qual veículo era utilizado para a publicidade? Aonde chegavam esses anúncios? 0 que era anunciado como vantagem para a compra de lotes? As propagandas atuais nos remetem a quais representações sobre essa colonização? Porque o termo "pioneiro" ainda é utilizado na publicidade para exaltar a cidade ou pessoas?

Alguns conceitos históricos podem ser trabalhados por intermédio da publicidade, como o de escravidão (concepções próprias de uma época expressadas na publicidade). Nos anúncios de jornais brasileiros do século XIX pretendiam vender, comprar ou achar escravos fugidos. Para vender ou comprar, valorizava-se o escravo como forte, obediente, jovem, trabalhador. Os escravos fugidos eram descritos fisicamente, e muitas vezes se especificava uma machucadura ou cicatriz para identificá-los. Através de tais anúncios, podemos verificar como o escravo era visto pelo senhor: mais como peça, instrumento de trabalho, mercadoria, mais animal do que um ser humano? Desta forma, o que era a escravidão? Como era a vida do escravo e como este era visto pelos senhores?

Se tivermos em vista que o passado só nos interessa pelas problemáticas postas no presente, 0 conceito de escravidão possibilita a reflexão sobre outros conceitos, como o de racismo, etnocentrismo e preconceito (cotejo entre publicidades e concepções de épocas diferentes).Como os negros são representados na publicidade atual? Existe racismo e/ou preconceito? Vale tomar como exemplo uma publicidade do carro "Pick Up Strada Fiat" que mostra a figura do negro de forma ridicularizada, em que este vai retirando e colocando objetos em seu cabelo, inclusive uma garrafa que sugere bebida alcoólica. 
Outra publicidade, a do desodorante anti-transpirante "Rexona Ebony", próprio para mulheres de pele morena e negra, mostra mulheres negras no trabalho, no ônibus e no shopping, o que é evidenciado pelo plano da câmera da cintura para cima, da cintura para baixo elas aparecem sambando. Tais publicidades reforçariam um estereótipo, resgatariam as raízes da etnicidade negra ou estariam mostrando que o negro ocupa lugares sociais antes não ocupados? 0 que podemos dizer sobre o nome do produto "Ebony", isto é, "ébano", geralmente utilizado para designar a cor de cavalos?

A publicidade nos oportuniza 0 trabalho com outros conceitos caros à História como: feminismo, imperialismo, capitalismo, globalização, imigração, identidade nacional, temporalidade, etc. Existem muitas possibilidades de uso da publicidade no ensino de História, dentre as quais a própria cultura midiática pode ser inquirida, ou seja, a História Imediata. A prática em se "desmontar" criticamente uma publicidade que vemos na TV, nos cartazes, nas revistas, nos jornais e nos outdoors no tempo atual, mesmo que seja no presente próximo, nos faz pôr em ação os mesmos métodos para analisar variados documentos elaborados em outras épocas e lugares. Partindo da prática de investigação Histórica através da publicidade, nós (os adultos) nos "sintonizamos" com as novas formas que crianças e adolescentes têm para apreender sua realidade interpelada constantemente pela mídia, servimo-nos da linguagem que para tais indivíduos é a mais inteligível. Se a cultura escolar tem interlocuções com outras instâncias de circulação de saberes, principalmente da mídia, ainda continua sendo o lugar que prima em promover a aprendizagem, e por isso, podemos fazer com que tais crianças e adolescentes aproveitem sua capacidade de captar rapidamente as mensagens da mídia para que incluam a reflexão, a análise, a crítica, no próprio ato de leitura da publicidade.

\section{Referências}

BARBOSA, R. apud SOUZA, R. F. Inovação educacional no século XIX: a construção do currículo da escola primária no Brasil. In: Cadernos Cedes, v. 21, 2000, p. 9-28.

BAUDRILLARD, J. 0 sistema dos objetos. 4 ed. São Paulo: Perspectiva, 2000. 
CAMPOS, C. C. G. Infância, mídia e cultura do consumo. In: GONDRA, J. G. (org.) História, infância e escolarização. Rio de Janeiro: Zahar: 7 letras, 2002.

CANCLINI, N. G. Consumidores e cidadãos. Conflitos multiculturais da globalização. 4 ed. Rio de Janeiro: Editora UFRJ, 2001.

CARLSON, D.; APPLE, M. Teoria educacional crítica em tempos incertos. In: HYPOLITO, Á. M.; GANDIN, L. A. (orgs.) Educação em tempos de incertezas. 2 ed. Belo Horizonte: Autêntica, 2003.

CHARLOT, B. Relação com o saber, formação dos professores e globalização. Questões para a educação hoje. Porto Alegre: Artmed, 2005.

CHARTIER, Roger. 0 mundo como representação. Estudos Avançados, v.5, n.11, p.173191, jan./abr.1991.

CURRAN, J. Meaning genre and contexte: the problematic of public knowledge in the new aundience studies. In: CURRAN, J.; GUREVITCHI, M. (org.) Mass media and society. Londres: Edward Arnold, 1991.

ELLSWORTH, E. Modos de endereçamento: uma coisa de cinema; uma coisa de educação também. In: SILVA, T. T. (org.) Nunca fomos humanos. Nos rastros do sujeito. Belo Horizonte: autêntica, 2001.

FERRAZ, F. C. A. Uma agenda alternativa para o debate sobre o uso escolar das fontes históricas. In: SCHIMIDT, M. A.; CAINELLI, M. R. (orgs.) III Encontro: Perspectivas do ensino de História, Curitiba: Aos Quatro Ventos, 1999.

FISCHER, R. M. B. Mídia e produção de sentidos: a adolescência em discurso. In: SILVA, L. H.(org.) A escola cidadã no contexto da globalização. 2 ed. Petrópolis: Vozes, 1998.

GUIMARÃES, E. de V. Consumo: seduções e questões do supermercado cultural. In ZILIOTTO, Denise Macedo. O consumidor: objeto da cultura. Petrópolis / Rio de Janeiro : Vozes, 2003.

KELLNER, D. Lendo imagens criticamente: em direção a uma pedagogia pós-moderna. In: SILVA, T. T. (org.) Alienígenas na sala de aula. Uma introdução aos estudos culturais em educação. Petrópolis, RJ: Vozes, 1995.

LÉVY, P. As tecnologias da inteligência. (trad. Carlos Irineu da Costa). Rio de Janeiro: Ed. 34, 1993.

MATOS, H. A política como entretenimento: uma visão do espetáculo midiático. In: BARROS FILHO, C. (org.) Comunicação na polis. Ensaios sobre mídia e política. Petrópolis / Rio de Janeiro : Vozes, 2002. 
METZ, C. A Significação no Cinema. Tradução de Jean-Claude Bernardet. 2 ed. São Paulo: Editora Perspectiva, 1977.

MOREIRA, A. da S. Cultura midiática e educação infantil. Educação e Sociedade, v. 24, n.85, Campinas, dez. 2003.

MUNAKATA, K. Por que Descartes criticou os estudos que realizou Colégio de La Flèche, mesmo admitindo que era "uma das mais célebres escolas da Europa"? In: TABORADA DE OLIVEIRA, M. A.; RANZI, S. M. F. (org.) História das disciplinas escolares no Brasil: contribuições para o debate. Bragança Paulista: EDUSF, 2003.

PAULA, S. Estudos culturais e receptor ativo. In Produção e recepção dos sentidos midiáticos. In: RUBIM, A. A. C.; BENTZ, M. G. (orgs.) 2 ed. Petrópolis / Rio de Janeiro : Vozes, 1998.

PEREIRA, R. M. R. Tudo ao mesmo tempo agora: considerações sobre a infância no presente. In: GONDRA, J. G. (org.) História, infância e escolarização. Rio de Janeiro: Zahar: 7 letras, 2002.

RODRIGUE, J. E. História em documento. Imagem e texto. 2 ed., São Paulo: FTD, 2002,4 vols.

SCHIMIDT, M. A.; GARCIA, T. B. 0 trabalho histórico em sala de aula. In: História e Ensino, v.9, Londrina: Ed. Humanidades; UEL, 2003.

SOUZA, R. F. Inovação educacional no século XIX: a construção do currículo da escola primária no Brasil. In: Cadernos Cedes, v. 21, 2000, p. 9-28.

VLAJKI, E. Democratization of serbs. Canadá: Revolt, 2001.

Sites

http://www.memoriadapropaganda.org.br/

http://www.kke.org.br/index.html 


\section{For a critical reading of the advertising language in classroom}

\section{ABSTRACT}

The present article proposes the discussion of the pedagogical function on the mediatic culture in modern societies. Suggests to researchers, teachers, and students the urgent need to transform the media into a subject of study within the school pedagogical practices, focusing mainly the publicity in the teaching of History.

Key words: mediatic culture; history teaching; publicity 